\title{
Dust Ignition of Pure and Encapsulated Paraffin Phase Change Materials
}

\author{
P.A. Boettcher ${ }^{1}$, H. Hu ${ }^{1}$, S.P.M. Bane ${ }^{2}$, M, McCarthy ${ }^{1}$, Y. Sun ${ }^{1, *}$ \\ ${ }^{I}$ Department of Mechanical Engineering and Mechanics, Drexel University, Philadelphia, PA \\ 19104, USA \\ ${ }^{2}$ School of Aeronautics and Astronautics, Purdue University, West Lafayette, IN 47907, USA
}

\begin{abstract}
In this study, the dependence of the flammable concentration on particle size is investigated for Phase Change Material (PCM) and Encapsulated Phase Change Material (EPCM) particles using a novel continuous particle dispersion apparatus into which a propane flame is introduced creating a test akin to the flash-point test for liquids. The results show that the threshold concentration is a strong function of particle size. For tested particles with size ranging from 290 $\mu \mathrm{m}$ to $750 \mu \mathrm{m}$, the threshold concentration is above the predictions based on an instantaneous heat transfer limit, and is approximately linear with the particle size, following a heat transfer limited ignition model. For sizes above $\approx 1 \mathrm{~mm}$, the particles behave like the bulk material, and ignition is not observed for the concentrations tested. The results obtained here are important for the safe construction, handling, and operation of systems using PCM and other particles.
\end{abstract}

Keywords: Dust ignition, Eicosane, Threshold flammable concentration, Logistic regression

*Corresponding author. Tel.:+1-215-895-1373; fax: +1-215-895-1478; Email: ysun@coe.drexel.edu. 


\section{Introduction}

Paraffin phase change materials (PCMs) are receiving an increasing interest as thermal storage solutions for both industrial and construction applications. Phase change materials are used in a number of different thermal storage applications spanning from cooling vests to building heating and cooling (Zalba, Marín, Cabeza and Mehling, 2003). Some of these phase change materials are designed to melt near ambient or room temperature conditions, for example, by refining or blending different paraffins together. For applications such as concentrated solar power and building envelope, the phase change material is encapsulated in a thin polymer shell with a higher melting temperature to maintain its shape. These encapsulated phase change material (EPCM) particles commonly range in size from $50 \mathrm{~nm}$ to $3 \mathrm{~mm}$ (Liu, Rao, Zhao, Huo and Li, 2015; Regin, Solanki and Saini, 2008). In addition, pure phase change materials are being considered as a thermal storage solution for indirect dry cooling towers of power plants (Sun et al., 2015) and can be produced through spray freezing processes in sizes varying from $100 \mu \mathrm{m}$ to several millimeters.

When assessing the dangers of using these materials, one measure is their flammability rating. Paraffin ranging from $\mathrm{C}_{17} \mathrm{H}_{36}$ to $\mathrm{C}_{23} \mathrm{H}_{48}$ has an NFPA 704 flammability rating of 1 with a flash point above $93^{\circ} \mathrm{C}$. Pre-heating of the bulk material is therefore required to create a flammable atmosphere. However, a dispersion of small particles is flammable without pre-heating (Eckhoff, 2003) and therefore both PCM and EPCM can create a flammable mixture by being either actively or accidentally dispersed in the air.

Some experimental data of ignition tests is available for dust mixture of various materials (Boilard, Amyotte, Khan, Dastidar and Eckhoff, 2013; Eckhoff, 2003; Eckhoff, 2012; Stahmer, 2015). However, due to the high number of possible flammable dusts, no data is available for the PCM of interest to current efforts such as eicosane. As a result, an experimental setup has been developed in this study to examine the flammability of candidate PCM materials. Specifically of interest are the flammability limits of particles dispersed in air and their threshold flammable concentration. To date, most experiments and analytical models for dust and spray ignitions have focused on the ignition temperature (Cassel and Liebman, 1959; Danzi, Marmo and Riccio, 2015; Huang, Risha, Yang and Yetter, 2009; Proust, 2006), minimum ignition energy (Boilard, Amyotte, Khan, Dastidar and Eckhoff, 2013), charge transferred, spark gap (Ballal and Lefebvre, 1979; Ballal and Lefebvre, 1981b; Proust, 2006; Schwenzfeuer and Glor, 1993), ignition time 
(Dreizin, 1996; Saitoh, Ishiguro and Niioka, 1982), quenching distances (Goroshin, Bidabadi and Lee, 1996), flame speeds (Ballal and Lefebvre, 1981a), particle burning rates (DesJardin, Felske and Carrara, 2005), and explosion pressure (Cashdollar, 2000; Cashdollar and Zlochower, 2007) which are critical quantities, but the question of this study is the fundamental relationship between the threshold flammable concentration and the particle size for a given type of PCM. In this study, ignition is treated as a statistical phenomenon due to the complexity of the contributing factors and a logistic regression analysis is performed on the available data. The prediction based on $50 \%$ chance for ignition is then placed into context of an analytical model to better understand the dependence of concentration on particle size.

The remainder of this paper is organized as follows. Section 2 describes the experimental setup, particles, and concentration measurements. The results from the ignition tests, the logistic regression analysis and analytical model are presented in Section 3. Section 4 reviews the conclusions drawn.

\section{Experimental Setup}

\subsection{Ignition Test}

Standard tests of dust flammability using the modified Hartmann apparatus or 20 L Siweck sphere are commonly performed to find the minimum explosive dust concentration, minimum ignition energies, and explosion pressures (Eckhoff, 2003; Kuchta, 1985). In the current study, a novel, simple test setup was constructed with a strong forced ignition source. The setup is constructed from off-the-shelf parts to give a Go/NoGo ignition result for the dispersed dust as its material, size, and concentration are varied. At the same time, the new experimental setup is designed to address the often-lamented non-uniform distribution of particles by improved dispersion and direct visualization of the test area.

The flammability test is modeled after flash point tests, such as the ASTM D56 Standard Test Method for Flash Point by Tag Closed Cup Tester (ASTM-D56, 1999) and the test setup created by Goroshin et al. used for quenching test of aluminum particles (Goroshin, Bidabadi and Lee, 1996) with further inspiration from Eggelston and Pryor (Eggleston and Pryor, 1967). In flash point and aluminum quenching tests, a mixture of fuel (vapor or solid) and air is created and a forced ignition source in the form of a propane torch is introduced. Figure 1 shows an image and a schematic of the experimental setup. It consists of two tubes with an inner diameter of $76.2 \mathrm{~mm}$ 
(3 in) and $304.8 \mathrm{~mm}$ (12 in) in length with a gap of approximately $30 \mathrm{~mm}$ between them. Both tubes are capped at each end with a fine metal mesh ( $0.15 \mathrm{~mm}$ opening, e.g. Mesh \#100 or finer) to hold the test particles at the bottom and stop particles at the top. In the current version, the lower tube is made of clear polycarbonate to easily see the particle dispersion during experiment and the upper tube is made of aluminum to withstand the heat release during an ignition event. The particles are dispersed by utilizing the upwards suction of the exhaust hood and the upward air flow from a nozzle fed with compressed air. The combination of both is used to uniformly distribute the particles in the test area between the tubes as shown in Figure 2. The air flow velocity in the test section varies between $0.4 \pm 0.1$ and $0.7 \pm 0.1 \mathrm{~m} / \mathrm{s}$ depending on the particles and desired concentration. For large particles, the dispersion by forced air is not feasible and particles are dropped from the top of the aluminum tube. The concentration is observed and measured using a high-speed camera and a uniform light source behind the particles as explained in the following section.

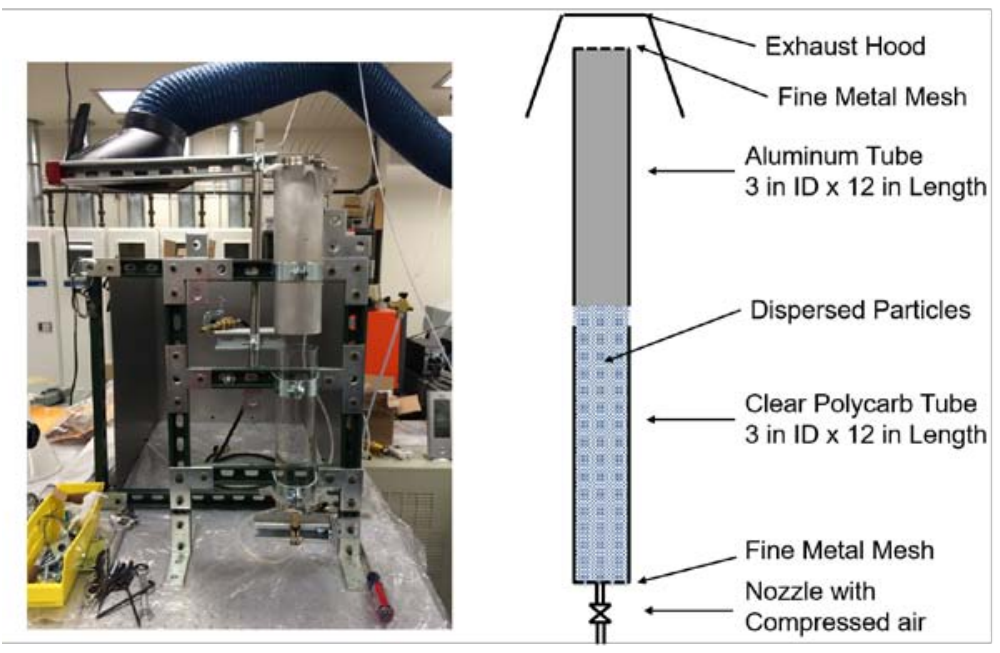

Figure 1. Photograph and schematic of the particle dispersion and ignition tester.

After a uniform particle distribution has been established, the mixture flammability is tested by inserting a standard propane flame into the gap between lower and upper tubes at the room temperature. The ignition test is evaluated on a Go/NoGo basis, assigning a 0 or NoGo to a test where the flame does not spread beyond the introduced propane torch and a 1 or Go to a test where the flame propagates away from the propane torch. To assess the flame spread, a highspeed camera (Edgertronic Monochrome) is used to observe the gap between the lower and 
upper tubes at a frame rate of 1000 frames per second and a resolution of $768 \times 768$, and an additional digital video camera is used to observe the full experimental setup. The final experiment is performed in a four-sided chamber ( 3 sides of steel and 1 side of polycarbonate) to allow for optical access while shielding the operator during the test.

\subsection{Concentration Measurement}

The concentration of the dust particles is the critical quantity under investigation in this study with the objective of assessing the threshold flammable concentration, $c_{\text {thr }}$, as a function of particle size, $D$, and material, $M$, i.e., $c_{\text {thr }}=f(D, M)$.

The concentration of particles is measured using the Beer-Lambert relation based on the light intensity observation on the high-speed camera. The initial, $I_{0}$, and final, $I$, light intensities are averaged over the observed illuminated test section as indicated in Figure 2 and the BeerLambert equation is given as

$$
\frac{I}{I_{0}}=\exp (-\alpha c l)
$$

where $\alpha$ is calibration constant related to the absorption cross section, $c$ is the particle concentration, and $l$ is the imaging depth perpenicular to the viewing plane in Fig. 2. Noting that the product of the concentration and the imaging depth, $c l$, is the mass loading per unit crosssectional area, $m / A$, the concentration measurements are calibrated using the following formula

$$
\ln \left(\frac{I}{I_{0}}\right)=-\alpha \frac{m}{A}+k
$$

allowing for a non-zero intercept, $k$, which comes from possible impurities in the sample (Brennan, 2008). 


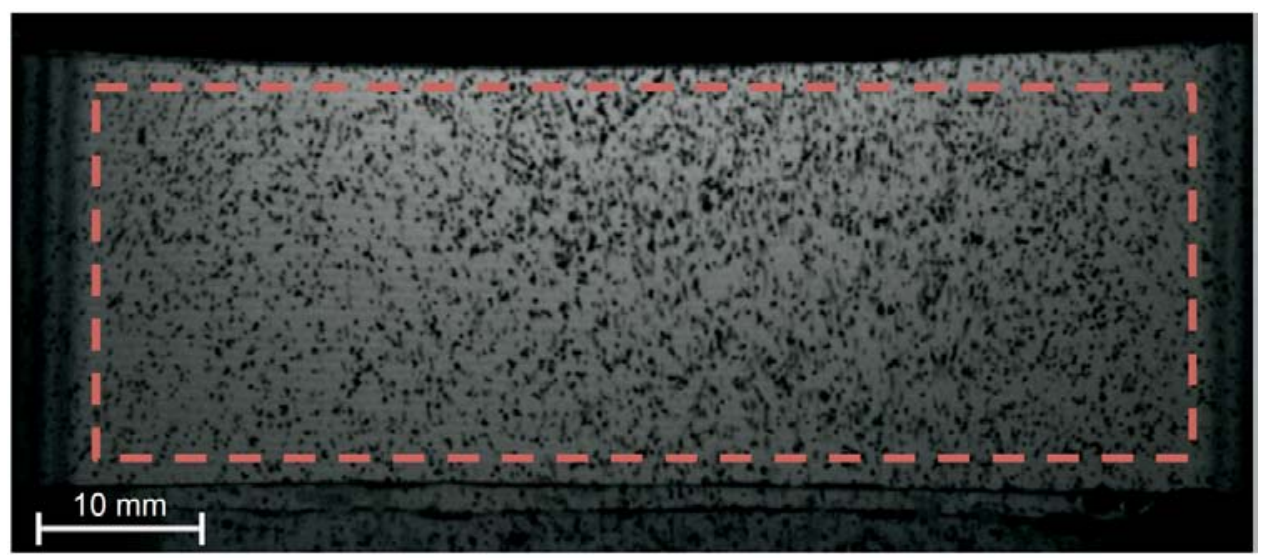

Figure 2. Particle distribution visualization captured by a high speed camera (Edgertronic Monochrome) between the upper and lower test tubes. From the highlighted section of the image, the dust concentration of BASF UN 3088 Micronal DS 5038 X Encapsulated PCM in air is calculated using a prior calibration.

In order to use Eq. (2) for calculating the dust concentration in the igition tests, the parameters $\alpha$ and $k$ were determined using separate particle concentration measurements. During the concentration tests, dusts with known mass $m$ (pre-measured with a microblance) were placed on a transparent plate illuminated from the back (cross-sectional area $A$ as shown in the highlighted section of Fig. 2). A high-speed camera (Edgertronic Monochrome) was used to capture the intensity of the light from the plate for cases with dust $(I)$ and without dust $\left(I_{0}\right)$. Figure 3 a shows the distribution of the diameter of eicosane particles used in the concentration tests as well as the ignition tests. Figure $3 \mathrm{~b}$ shows the relative light intensity of these eicosane particles together with BASF microencapsulated PCM particles $(330 \mu \mathrm{m})$ as a function of dust mass loading per unit area, $m / A$ from the concentration tests. In Fig. 3b, the symbols represent the experimental data of the concentration tests, and the dashed lines represent the fitting curve by performing linear regression with the experimental data. Table 1 shows the slope, $\alpha$, intercept, $k$, and coefficient of determination, $R^{2}$, of the linear fitting of the concentration test data. It can be seen that $R^{2}>0.97$ for all eicosane particles and $R^{2}>0.94$ for all BASF microencapsulated PCM particles, indicating that the data points follow the linear relation represented with Eq. (2) . 
The fitted $\alpha$ and $k$ were then used to calculate the concentration of dust in the ignition tests. In the ignition tests, the intensity of the light across the dusts was analyzed using the photos captured by the high-speed camera. The mass loading was back calculated with the relative light intensity using Eq. (2). From the mass loading the particle concentration can be calculated from the tube diameter and accounting for the fact that the tube is round and not square.
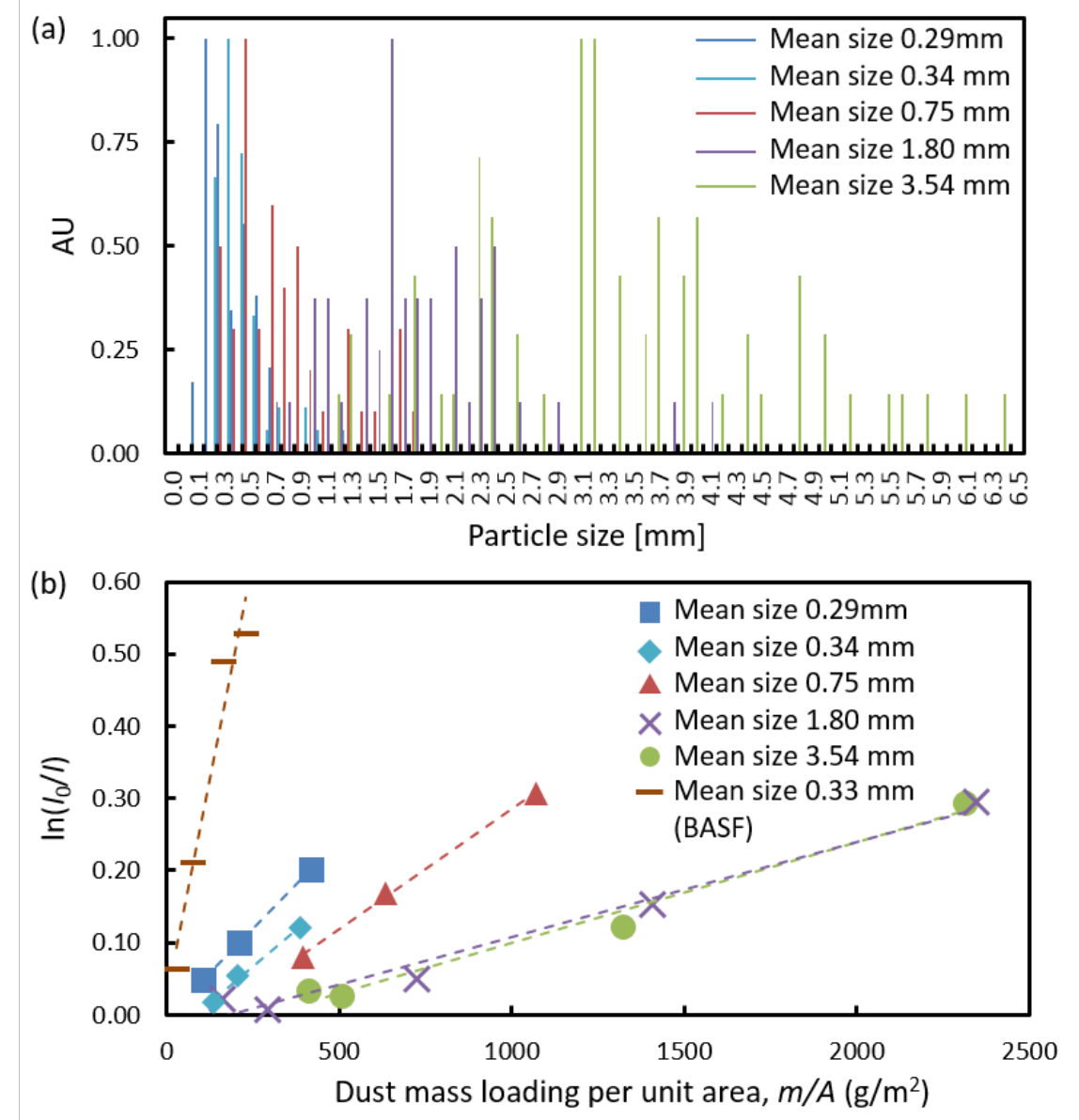

Figure 3. (a) Size distribution of eicosane particles for concentration tests. (b) Relative light intensity as a function of particle mass loading for eicosane and BASF microencapsulated PCM particles.

TABLE I. The slope, intercept and linear fitting $R^{2}$ values of the concentration test data. 


\begin{tabular}{lcccccc}
\hline & $\begin{array}{c}0.29 \mathrm{~mm} \\
\text { eicosane }\end{array}$ & $\begin{array}{c}0.34 \mathrm{~mm} \\
\text { eicosane }\end{array}$ & $\begin{array}{c}0.75 \mathrm{~mm} \\
\text { eicosane }\end{array}$ & $\begin{array}{c}1.80 \mathrm{~mm} \\
\text { eicosane }\end{array}$ & $\begin{array}{c}3.54 \mathrm{~mm} \\
\text { eicosane }\end{array}$ & $\begin{array}{c}0.33 \mathrm{~mm} \\
\text { BASF }\end{array}$ \\
\hline$\alpha\left[\mathrm{m}^{2} / \mathrm{kg}\right]$ & 0.4583 & 0.4086 & 0.333 & 0.1318 & 0.1391 & 2.439 \\
$k$ & -0.001 & -0.0355 & -0.0484 & -0.0244 & -0.0391 & 0.0208 \\
$R^{2}$ & 0.9999 & 0.9906 & 0.998 & 0.978 & 0.9803 & 0.9464 \\
\hline
\end{tabular}

\section{Results}

\subsection{Ignition Test}

In this study, dust ignition tests were performed for $99.9 \%$ pure eicosane $\left(\mathrm{C}_{20} \mathrm{H}_{42}\right)$ of five different sizes, $290 \mu \mathrm{m}, 340 \mu \mathrm{m}, 750 \mu \mathrm{m}, 1.80 \mathrm{~mm}$, and $3.54 \mathrm{~mm}$, as well as encapsulated PCM particles (BASF UN 3088 Micronal DS 5038 X) with an average size of $330 \mu \mathrm{m}$. Figure 4 shows the experimental results of ignition tests for eicosane particles with diameters of (a) $290 \mu \mathrm{m}$, (b) $340 \mu \mathrm{m}$, and (c) $750 \mu \mathrm{m}$. For the $290 \mu \mathrm{m}$ diameter eicosane particles, transition from NoGo to Go occurs between a concentration of $4.2 \mathrm{~kg} / \mathrm{m}^{3}$ and $8.7 \mathrm{~kg} / \mathrm{m}^{3}$ as shown in Fig. $4 \mathrm{a}$. As the particle size increases to $340 \mu \mathrm{m}$ and $750 \mu \mathrm{m}$, as shown in Figs. $4 \mathrm{~b}$ and $4 \mathrm{c}$, the NoGo/Go transitions take place for concentration ranges of $1.5-20 \mathrm{~kg} / \mathrm{m}^{3}$ and $22-98 \mathrm{~kg} / \mathrm{m}^{3}$, respectively.

In order to define the threshold concentration for ignition with a limited number of data points, logistic regression analysis is performed to calculate a cumulative probability distribution for the ignition data. This distribution then gives the probability of a "Go" result (ignition) for certain test parameters (e.g., particle concentration). The logistic distribution has been used to analyze the results of spark ignition (Bane, 2010) and hot surface ignition (Colwell and Reza, 2005) tests where a single minimum threshold spark energy or surface temperature could not be identified. The current experimental results are treated using a binary outcome model with a binary result $y$, where $y=1$ for a "Go" (ignition) and $y=0$ for a "No Go" (no ignition) for a given particle mass concentration $c$. The cumulative probability distribution for a "Go" at concentration $c$ can be defined as $P(c)=\operatorname{Probability}(y=1 ; c)$. All the values of concentration and the binary results for the $\mathrm{n}$ tests are represented collectively using the likelihood function (Bane, 2010)

$$
L=\prod_{i=1}^{n} P\left(c_{i}\right)^{v_{i}}\left(1-P\left(c_{i}\right)\right)^{1-y_{i}}
$$

The probability $P(c)$ is assumed to be represented with the parametric logistic distribution function 


$$
P(c)=\frac{1}{1+\exp \left(-\beta_{0}-\beta_{1} c\right)}
$$

where $\beta_{0}$ and $\beta_{1}$ are parameters that are estimated by maximizing the likelihood function (Eq. (3)) (Bane, 2010). The probability distribution curves are plotted along with the experimental data points in Fig. 4 and for experiments with overlapping the upper (UCL) and lower (LCL) 95\% confidence levels. The threshold concentration, $c_{\mathrm{thr}}$, above which ignition occurs can be determined by solving $P\left(c_{\text {thr }}\right)=50 \%$ (Bane, 2010; Colwell and Reza, 2005). The resulted threshold flammable concentrations for eicosane particles with diameters of $290 \mu \mathrm{m}, 340 \mu \mathrm{m}$, and $750 \mu \mathrm{m}$ using $P\left(c_{\text {thr }}\right)=50 \%$ are $7.1 \mathrm{~kg} / \mathrm{m}^{3}, 10.1 \mathrm{~kg} / \mathrm{m}^{3}$ and $57.6 \mathrm{~kg} / \mathrm{m}^{3}$, respectively. 

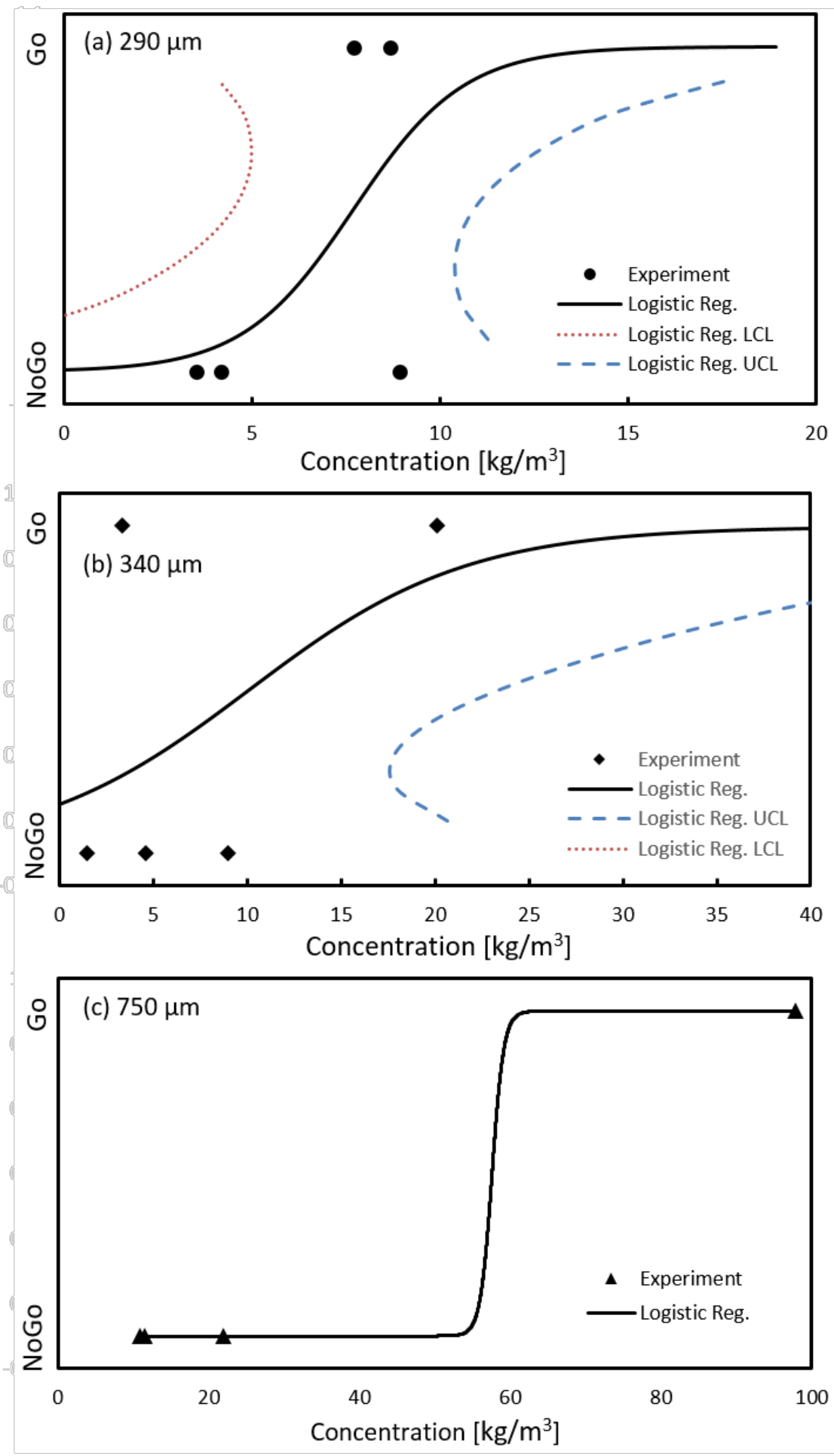

Figure 4. Eicosane ignition results as a function of concentration for particle sizes of (a) $290 \mu \mathrm{m}$, $340 \mu \mathrm{m}$, and $750 \mu \mathrm{m}$. 
As for very large cast particles of 1.80 and $3.54 \mathrm{~mm}$ diameters, no ignition is observed at the highest concentrations observable during the test. For these large particles, the dust characterization no longer seems applicable as the particles behave more like the bulk material and would therefore require extended heating to develop a flammable atmosphere in their vicinity.

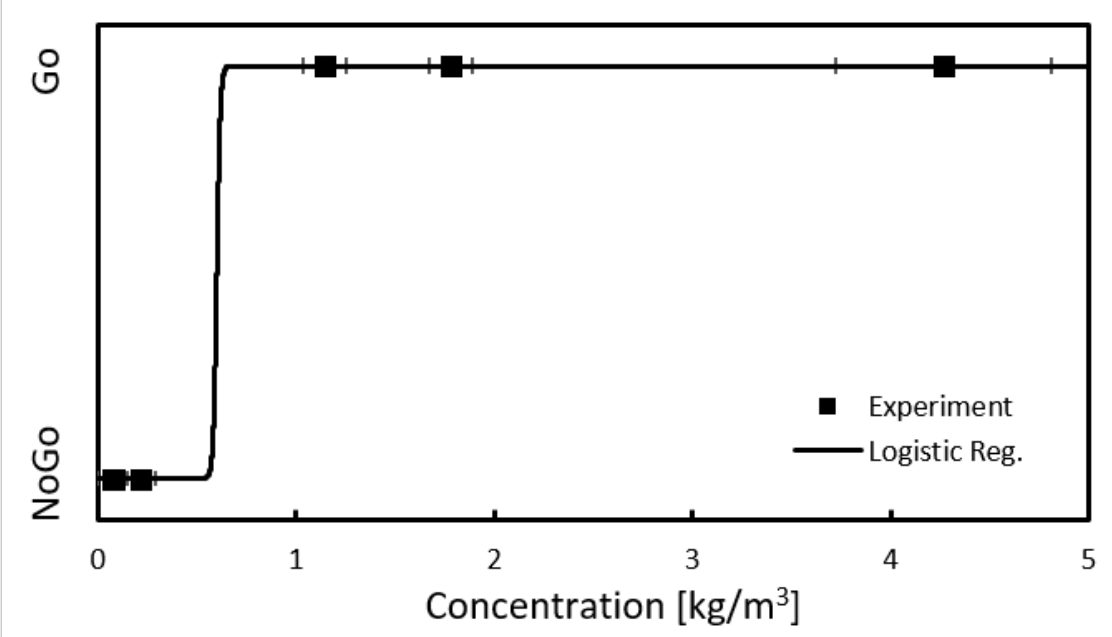

Figure 5. BASF Micronal ignition results as a function of concentration (particle size $330 \mu \mathrm{m}$ ).

The second material type investigated is a sample of commercial BASF UN 3088 Micronal DS $5038 \mathrm{X}$ which is made up of a hard encapsulating polymer material and an internal PCM core. Due to the availability of the commercial particles, only the EPCM particles with diameter of $330 \mu \mathrm{m}$ are tested. Figure 5 shows the experimental results of the ignition tests of BASF EPCM particles along with the probability curve from the logistic regression analysis. The experimental results for the BASF Micronal particles show a transition from NoGo to Go between a concentration of 0.08 and $1.14 \mathrm{~kg} / \mathrm{m}^{3}$, and the threshold flammable concentration for the EPCM particles is $0.6 \mathrm{~kg} / \mathrm{m}^{3}$ from the logistic regression with $P\left(c_{\text {thr }}\right)=50 \%$.

Figure 6 shows the threshold dust concentration for ignition as a function of particle size for eicosane from the present work and other common materials from literature (Eckhoff, 2003). As shown in Fig. 6, for all materials, the threshold concentration increases with the particle size. But the rate of increase in threshold concentration with increasing particle size is different from one material to another. 


\subsection{Analytical Model of Surface Area to Volume Ratio Required for Ignition}

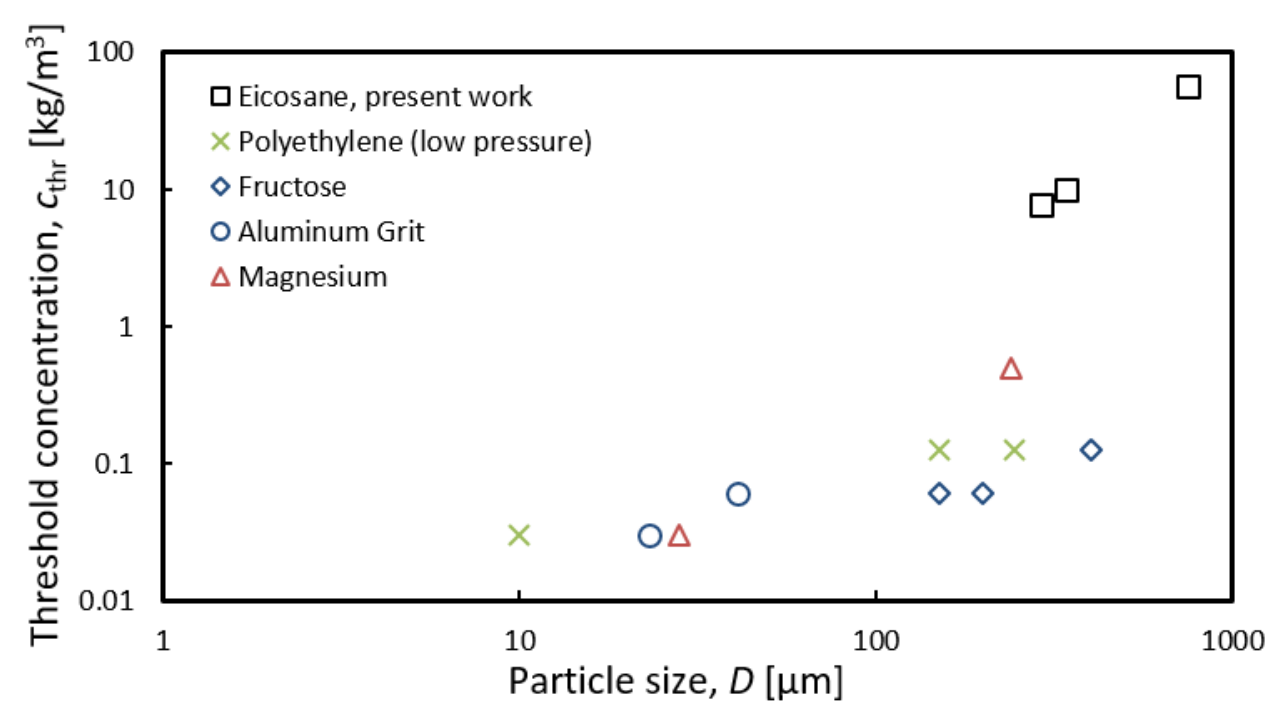

Figure 6. Threshold flammable dust concentrations as a function of particle size for various materials (data from appendix A of (Eckhoff, 2003)).

For very small particles, the particle surface-area-to-volume ratio is extremely large, which results in very fast heat transfer. Therefore, the particle will ignite as long as the energy propagated to the particle is larger enough to melt and vaporize the melt to form a fuel/air mixture. The energy required to ignite a particle is equal to the energy needed to melt and vaporize a solid particle as

$$
Q_{\text {required }}=\frac{\pi}{6} \rho_{\mathrm{PCM}} D^{3}\left[h_{\mathrm{SL}}+h_{\mathrm{LV}}+c_{\mathrm{p}}\left(T_{\mathrm{f}}-T_{\mathrm{a}}\right)\right]
$$

where $h_{\mathrm{SL}}$ and $h_{\mathrm{LV}}$ represent the enthalpy of melting and enthalpy of vaporization, respectively, and $\rho_{\mathrm{PCM}}$ the density of eicosane. The sensible heat of the particles during ignition is estimated with $c_{\mathrm{p}}\left(T_{f}-T_{\mathrm{a}}\right)$, where $c_{\mathrm{p}}$ is the heat capacity and is assumed constant, $T_{\mathrm{f}}$ the boiling point, and $T_{\mathrm{a}}$ the ambient temperature.

The energy generated by combustion of one particle is

$$
Q_{\mathrm{R}}=\frac{\pi}{6} \rho_{\mathrm{PCM}} D^{3} h_{\mathrm{R}}
$$

where $h_{\mathrm{R}}$ represents the enthalpy of combustion of PCM. Assuming the particles in the dust are well dispersed with the average distance between the particles of $s$, the flame of one ignited 
particle will reach one neighbor particle when it propagates by $s / 2$ (or equivalently, occupying a spherical volume with a diameter of $s$ ). Assuming the energy is dispersed uniformly, the energy density in the spherical volume is thus $6 Q_{\mathrm{R}} /\left(\pi \mathrm{s}^{3}\right)$. Assuming instantaneous heat transfer, where the heat transfer time (i.e., the time for PCM particle to melt and vaporize) is much smaller than the time for flame to propagate by $s / 2$, the energy that the neighbor particle absorbs is equal to the product of the energy density and the volume of this particle

$$
Q_{\text {in }}=\left(\frac{D}{s}\right)^{3} Q_{\mathrm{R}}
$$

When $Q_{\text {in }} \geq Q_{\text {required }}$, the particle will ignite. The maximum spacing that enables ignition can be obtained using $Q_{\text {in }}=Q_{\text {required }}$ as

$$
s_{\text {thr }}=\left(\frac{h_{\mathrm{R}}}{h_{\mathrm{SL}}+h_{\mathrm{LV}}+c_{\mathrm{p}}\left(T_{\mathrm{f}}-T_{\mathrm{a}}\right)}\right)^{1 / 3} D
$$

The threshold flammable concentration can hence be calculated as the mass of a particle divided by the space it occupies following

$$
c_{\mathrm{thr}}=\frac{\pi \rho_{\mathrm{PCM}}}{6}\left(\frac{D}{s_{\mathrm{thr}}}\right)^{3}
$$

Substituting Eq. (8) to Eq. (9) gives the threshold flammable concentration as

$$
c_{\mathrm{thr}}=\frac{\pi \rho_{\mathrm{PCM}}}{6 h_{\mathrm{R}}}\left[h_{\mathrm{SL}}+h_{\mathrm{LV}}+c_{\mathrm{p}}\left(T_{\mathrm{f}}-T_{\mathrm{a}}\right)\right]
$$

From Eq. (10), it is evident that assuming instantaneous heat transfer, the threshold flammable concentration is independent of the particle size. For eicosane, the heat of reaction is $h_{\mathrm{R}}=13,316$ $\mathrm{kJ} / \mathrm{mol}$, the latent heat of melting and vaporization are $h_{\mathrm{SL}}=69 \mathrm{~kJ} / \mathrm{mol}$ and $h_{\mathrm{LV}}=78 \mathrm{~kJ} / \mathrm{mol}$, respectively, the heat capacity is $c_{\mathrm{p}}=664 \mathrm{~J} / \mathrm{mol} \mathrm{K}$, and the flash boiling temperature is $T_{\mathrm{f}}=$ $113^{\circ} \mathrm{C}$. For an ambient temperature of $T_{\mathrm{a}}=25^{\circ} \mathrm{C}$, using Eq. (10) gives the threshold flammable concentration of eicosane to be $6.29 \mathrm{~kg} / \mathrm{m}^{3}$.

The instantaneous heat transfer assumption is valid only when the heat transfer is fast compared to flame propagation. As particle size increases, the thermal resistances of the particle increases, leading to slower melting and vaporization processes. The instantaneous heat transfer assumption breaks down when the heat transfer time scale is greater than the flame propagation 
time scale. Under this circumstance, heat transfer becomes the limiting factor of frame propagation. Inside the air/dust mixture, the energy released from the chemical reaction is assumed to be in competition with the energy lost to particle phase change and heat transfer to the surroundings. Therefore, the decrease in the time required for particle phase change will transition the air/dust system from non-ignition to ignition.

For cases where heat transfer is not instantaneous (i.e., in heat transfer limited regime), when a particle ignites, the neighbor particle is not able to absorb the maximum possible energy as represented by Eq. (7). Here we perform a scaling analysis to identify the critical parameters for ignition. After one particle has ignited, the surrounding air is heated up from the original ambient temperature, $T_{\mathrm{a}}$ to a higher temperature, $T_{\text {high }}$. Assuming the combustion takes place in a constant volume, the heat released by the combustion of the particle is dispersed uniformly in a spherical volume with a diameter of $s$ (the average distance between PCM particles). The increase in air temperature is determined based on energy conservation as $T_{\text {high }}-T_{\mathrm{a}} \sim \rho_{\mathrm{PCM}} D^{3} h_{\mathrm{R}} /\left(c_{\mathrm{p} \text {,air }} \rho_{\text {air }} s^{3}\right)$, where $c_{\mathrm{p}, \text { air }}$ and $\rho_{\text {air }}$ are the heat capacity and density of air, respectively. Heat is then transferred from the air to the neighbor particles of the combusted particle by convection (assuming radiation is negligible). The total amount of the energy transferred to a neighbor particle by air can be expressed as

$$
Q_{\mathrm{in}} \sim \int_{0}^{t} h_{\mathrm{air}} \pi D^{2}\left[T_{\mathrm{s}}(\tau)-T_{\mathrm{w}}(\tau)\right] d \tau
$$

where $h_{\text {air }}$ is the convective heat transfer coefficient, $t$ the time for the phase change (melting and vaporization) to complete, and $T_{\mathrm{s}}$ and $T_{\mathrm{w}}$ the surrounding air temperature and the particle surface temperature, respectively. During convective heat transfer with the air, the particle surface temperature, $T_{\mathrm{w}}$, increases from the ambient temperature, $T_{\mathrm{a}}$ of $25^{\circ} \mathrm{C}$ at the initial stage to the flash point, $T_{\mathrm{f}}$ of $113^{\circ} \mathrm{C}$, before it ignites. Meanwhile, the temperature of the surrounding air, $T_{\mathrm{s}}$, reduces from $T_{\text {high }}$ to $T_{\mathrm{s} \text {,final }}$ and this temperature reduction can be estimated based on energy conservation, following $T_{\text {high }}-T_{\mathrm{s} \text {,final }} \sim \rho_{\mathrm{PCM}} D^{3}\left[h_{\mathrm{SL}}+h_{\mathrm{LV}}+c_{\mathrm{p}}\left(T_{\mathrm{f}}-T_{\mathrm{a}}\right)\right] /\left(c_{\mathrm{p}, \text { air }} \rho_{\mathrm{air}} s^{3}\right)$. It is noted that, based on the properties of the PCM particles and the air, $T_{\text {high }}-T_{\text {s,final }}$ is only $\sim 1.5 \%$ of $T_{\text {high }}-T_{\text {a }}$, indicating that the temperature change in surrounding air is negligible during convective heat transfer with the neighbor particle. Because the temperature increase of the 
particle surface is $T_{\mathrm{f}}-T_{\mathrm{a}}=88 \mathrm{~K}$, much smaller compared with $T_{\text {high }}$ of $\sim 2000 \mathrm{~K}$ when radiation is neglected, Eq. (11) can hence be simplified as $Q_{\text {in }} \sim h_{\text {air }}\left(T_{\text {high }}-T_{\mathrm{a}}\right) \pi D^{2} t$. Recall that the convective heat transfer coefficient scales with inverse of the PCM particle diameter following $h_{\text {air }} \propto \mathrm{Nu}_{\text {air }} k_{\text {air }} / D$, where $k_{\text {air }}$ is the thermal conductivity of air. In addition, the heat transfer time, $t$, scales with the particle diameter following $t \propto D / \alpha$, where $\alpha$ is the rate of phase change (with unit of $\mathrm{m} / \mathrm{s}$ ) and is a function of the thermal conductivity and latent heat of the PCM particle. Submitting the expressions of $h_{\text {air }}, T_{\text {high }}-T_{\mathrm{a}}$, and $t$ into $Q_{\text {in }} \sim h_{\text {air }}\left(T_{\text {high }}-T_{\mathrm{a}}\right) \pi D^{2} t$ gives the total amount of energy transferred to a neighbor particle of the combusted particle as $Q_{\mathrm{in}} \sim \pi \mathrm{Nu}_{\text {air }} k_{\text {air }} \rho_{\mathrm{PCM}} D^{5} h_{\mathrm{R}} /\left(\alpha c_{\mathrm{p} \text {,air }} \rho_{\text {air }} s^{3}\right)$. Setting $Q_{\mathrm{in}}=Q_{\text {required }}$ gives the critical condition for ignition as

$$
\frac{D^{2}}{s_{\mathrm{thr}}^{3}} \propto \frac{\left[h_{\mathrm{SL}}+h_{\mathrm{LV}}+c_{\mathrm{p}}\left(T_{\mathrm{f}}-T_{\mathrm{a}}\right) \mid c_{\mathrm{p}, \mathrm{air}} \rho_{\text {air }} \alpha\right.}{6 h_{\mathrm{R}} \mathrm{Nu}_{\mathrm{air}} k_{\mathrm{air}}}
$$

It is noted that, the right-hand of Eq. (12) does not change with the particle size, making $D^{2} / s_{\text {thr }}^{3}=$ const. Defining the particle surface area density of the dust as $S V=\pi D^{2} / s^{3}$, the critical surface-volume-ratio $S V_{\mathrm{thr}}$ is independent of the particle size. It is helpful to connect this surface-to-volume ratio to the threshold flammable concentration $c_{\text {thr }}$ and particle size $D$. Assuming that there are $n$ number of particles in the total volume $V_{\text {air/particle,total }}$, the total particle surface area is $S_{\text {particle }}=\pi D^{2} n$. The total volume can be expressed in terms of the concentration, the particle size, and number of particles as $V_{\text {air/particle,total }}=\pi D^{3} \rho_{\mathrm{PCM}} n /(6 c)$. The particle surface area density can thus be written as

$$
S V=\frac{6 c}{\rho_{\mathrm{PCM}} D}
$$

For certain materials under given conditions (moisture, temperature, applied energy density, etc.), this surface-to-volume ratio determines the contact area density between the fuel dust and oxidizer, and thus affects the flammability of the material. A large surface-to-volume ratio represents a well-dispersed particle cloud in the air, which is easier to ignite. Since the threshold surface-to-volume ratio is not a function of particle size, based on Eq. (13), the threshold flammable concentration will scale linearly with the particle size. In experiments, due to various non-idealities (e.g. uniform particle size, non-purities, etc.), the linear relation between $c_{\text {thr }}$ and 
$D$ may not be followed exactly. However, the trend of increasing $c_{\mathrm{thr}}$ with $D$ can be observed as in Fig. 6 where literature data are available for multiple particle sizes of the same material (Eckhoff, 2003).

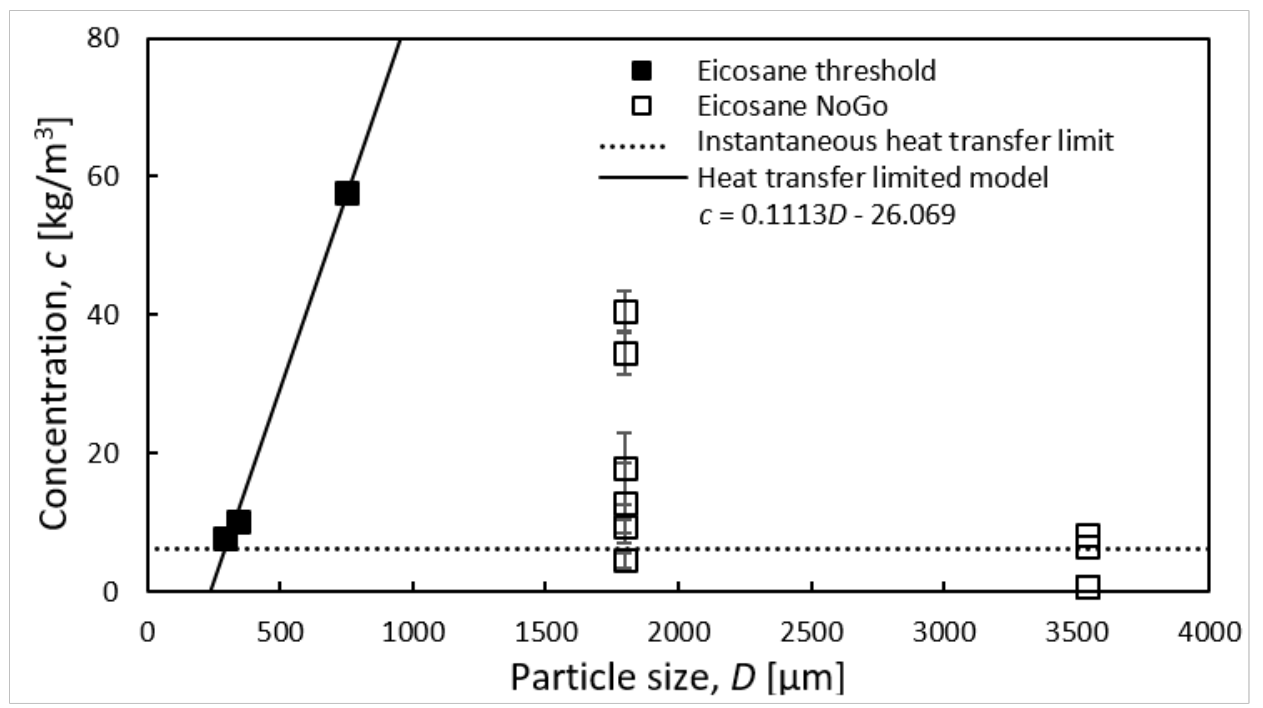

Figure 7. Dust concentrations as a function of particle size for eicosane.

Figure 7 shows the threshold concentration as a function of particle size for eicosane particles based on the ignition experiments and logistic regression analysis (represented with solid symbols). The heat transfer limited model predicts a linear relation between the threshold flammable concentration and the particle size, but does not give the exact analytical equation for the linear relation. Therefore, linear fitting is performed for experimentally determined threshold flammable concentration, resulting in a fitting equation of $c=0.1113 D-26.069$ for eicosane. The coefficient of determination of the fitting is $R^{2}=0.996$, demonstrating a good linearity between the threshold flammable concentration and the particle size. The dashed line shows the prediction based on the instantaneous heat transfer limit from Eq. (10), which gives the lower bound of the threshold concentration regardless of the particle size. The threshold concentrations from the experiments are all beyond the instantaneous heat transfer limit. The open symbols represent the ignition test results for eicosane particles with diameters of $1.80 \mathrm{~mm}$ and $3.54 \mathrm{~mm}$. For these two particle sizes, ignition is not observed with the highest concentration tested. 


\section{Conclusion}

In this study, the threshold flammable concentrations of PCM and EPCM particles of different sizes are experimentally investigated. The flammability characterization for both eicosane and Micronal encapsulated particles shows that both can create flammable mixtures in air. For eicosane, multiple sizes were available which showed that the threshold concentration of particles necessary for ignition is a function of the particle size. However, as the particle size increases to $1.80 \mathrm{~mm}$ and $3.54 \mathrm{~mm}$ in diameter, the particle/air mixture behaves like a bulk material such that the safety assessment of these particles should be approached like the flammability characterization of the bulk material, i.e., as by its flash point.

The current study also attempts to consolidate the available experimental data of particle size and threshold concentration by considering a combined quantity, the particle surface area density, as an indicator for particle flammability. For a given material, a linear relationship between the threshold concentration and the particle size is predicted by using the heat transfer limited ignition model. Although available data in the literature and present experiment results qualitatively support this analysis, further investigation and model refinement are required to better quantify this flammability threshold.

\section{Acknowledgements}

This study was supported by the Electric Power Research Institute under Contract No. 10002061 and National Science Foundation under Grant No. CBET-1357918 and CBET0968927. The authors also thank Dr. Miller, Dr. Cernansky, Michael Stichter, and Jeremy Robbins for generously agreeing to let us use their facilities and Mbalu Forna-Delo for helping with the experimental setup.

\section{References}

Alfa Aesar Safety Data Sheet n-Eicoane, http://www.alfa.com/content/msds/USA/A13853.pdf, Accessed: 2015-08-15.

ASTM-D56, (1999). Standard test method for flash point by Tag closed tester. American Society for Testing and Materials West Conshohocken, PA.

Ballal, D., Lefebvre, A., (1979). Ignition and flame quenching of flowing heterogeneous fuel-air mixtures. Combustion and Flame, 35, 155-168.

Ballal, D., Lefebvre, A., (1981a). Flame propagation in heterogeneous mixtures of fuel droplets, fuel vapor and air, Symposium (International) on combustion. Elsevier, pp. 321-328.

Ballal, D.R., Lefebvre, A., (1981b). A general model of spark ignition for gaseous and liquid fuel-air mixtures, Symposium (international) on combustion. Elsevier, pp. 1737-1746. 
Bane, S.P.M., (2010). Spark ignition: experimental and numerical investigation with application to aviation safety. California Institute of Technology.

Boilard, S.P., Amyotte, P.R., Khan, F.I., Dastidar, A.G., Eckhoff, R.K., (2013). Explosibility of micron- and nano-size titanium powders. Journal of Loss Prevention in the Process Industries, 26, 1646-1654.

Brennan, M., (2008). A Practical Approach to Quantitative Metal Analysis of Organic Matrices: Wiley.

Cashdollar, K.L., (2000). Overview of dust explosibility characteristics. Journal of Loss

Prevention in the Process Industries, 13, 183-199.

Cashdollar, K.L., Zlochower, I.A., (2007). Explosion temperatures and pressures of metals and other elemental dust clouds. Journal of Loss Prevention in the Process Industries, 20, 337-348. Cassel, H., Liebman, I., (1959). The cooperative mechanism in the ignition of dust dispersions. Combustion and Flame, 3, 467-475.

Colwell, J.D., Reza, A., (2005). Hot surface ignition of automotive and aviation fluids. Fire Technology, 41, 105-123.

Danzi, E., Marmo, L., Riccio, D., (2015). Minimum Ignition Temperature of layer and cloud dust mixtures. Journal of Loss Prevention in the Process Industries, 36, 326-334.

DesJardin, P.E., Felske, J.D., Carrara, M.D., (2005). Mechanistic model for aluminum particle ignition and combustion in air. Journal of Propulsion and Power, 21, 478-485.

Dreizin, E.L., (1996). Experimental study of stages in aluminium particle combustion in air. Combustion and Flame, 105, 541-556.

Eckhoff, R., (2003). Dust Explosions in the Process Industries: Identification, Assessment and Control of Dust Hazards: Elsevier Science.

Eckhoff, R.K., (2012). Does the dust explosion risk increase when moving from $\mu \mathrm{m}$-particle powders to powders of nm-particles? Journal of Loss Prevention in the Process Industries, 25, 448-459.

Eggleston, L.A., Pryor, A.J., (1967). The limits of dust explosibility. Fire Technology, 3, 77-89. Goroshin, S., Bidabadi, M., Lee, J., (1996). Quenching distance of laminar flame in aluminum dust clouds. Combustion and Flame, 105, 147-160.

Huang, Y., Risha, G.A., Yang, V., Yetter, R.A., (2009). Effect of particle size on combustion of aluminum particle dust in air. Combustion and Flame, 156, 5-13.

Kuchta, J.M., (1985). Investigation of Fire and Explosion Accidents in the Chemical, Mining, and Fuel-related Industries: A Manual: U.S. Department of the Interior, Bureau of Mines.

Liu, C., Rao, Z., Zhao, J., Huo, Y., Li, Y., (2015). Review on nanoencapsulated phase change materials: Preparation, characterization and heat transfer enhancement. Nano Energy, 13, 814826.

Proust, C., (2006). A few fundamental aspects about ignition and flame propagation in dust clouds. Journal of Loss Prevention in the Process Industries, 19, 104-120.

Regin, A.F., Solanki, S.C., Saini, J.S., (2008). Heat transfer characteristics of thermal energy

storage system using PCM capsules: A review. Renewable and Sustainable Energy Reviews, 12, 2438-2458.

Saitoh, T., Ishiguro, S., Niioka, T., (1982). An experimental study of droplet ignition characteristics near the ignitable limit. Combustion and Flame, 48, 27-32.

Schwenzfeuer, K., Glor, M., (1993). Tests to determine the ignition of dust by brush discharges. Journal of electrostatics, 30, 115-122.

Stahmer, K.W., (2015). GESTIS-DUST-EX Database Combustion and explosion characteristics of dusts, IFA.

Sun, Y., McCarthy, M., Cho, Y.I., Boettcher, P., Hu, H., Shi, B., Xie, Q., (2015). Systems and Methods of Using Phase Change Material in Power Plants. Application No.: 14/601,616.

Zalba, B., Marın, J.M., Cabeza, L.F., Mehling, H., (2003). Review on thermal energy storage with phase change: materials, heat transfer analysis and applications. Applied Thermal

Engineering, 23, 251-283. 